\title{
Pathway for China's Green Energy Growth: A Long-Term Strategic Perspective
}

\author{
Xiaoling Wang, Chunyou Wu, and Jatin Nathwani
}

\begin{abstract}
China, the largest populous country, energy consumer, and overall $\mathrm{CO}_{2}$ emitter in the world, is facing dual pressure arising from challenges both at home and from abroad to become sustainable society. To address the "multi-lemma" of economic prosperity, energy security, social development, and ecological prudence, China is in desperate need of a green growth strategy. One approach is to focus on the energy sector to transition to a Green, Reliable, Effective, Affordable, and Thrifty (GREAT) energy system to create sustainable the economic opportunities but reduce environmental pressures at the same time. We describe here an analytical framework that provides a long-term comprehensive $g$ policy to support the GREAT energy scheme.
\end{abstract}

Index Terms - China, green growth, the GREAT energy system, energy strategy, SCORE analysis, LCSEF.

\section{INTRODUCTION}

The Economic and Social Commission for Asia and the Pacific (UNESCAP) identifies green growth as "growth in GDP that maintains or restores environmental quality and ecological integrity, while meeting the needs of all people with the lowest possible environmental impacts." The Organization for Economic Co-operation and Development (OECD) considers green growth as "fostering economic growth and development while ensuring that natural assets continue to provide the resources and environmental services on which our well-being relies". Therefore, green growth strategy is to promote environmentally benign, practices based on a lower carbon footprint that allow integration of economic development, social equity, and environmental conservation in a sustainable way. Moreover, a systematic model that shifts from an energy-intensive regime to an economic, clean, and carbon-neutral growth paradigm is required to achieve green growth.

Furthermore, as the basis and engine of economy, the energy system, with its major impact on greenhouse gas (GHG) emissions and environmental degradation, has been playing a significant and unique role in fostering regional green growth. A green engine that has decreasing environmental impact during its life-cycle is the centerpiece of all green growth scenarios [1]. Innovation and transformation of energy systems are therefore a key pathway

Manuscript received July 7, 2014; revised November 10, 2014.

Xiaoling Wang is with the Dalian University of Technology, Dalian, China. She is also with the University of Waterloo, Waterloo, Canada (e-mail: x538wang@uwaterloo.ca).

Chunyou Wu is with the Dalian University of Technology, Dalian, China (e-mail: wucy@dlut.edu.cn).

Jatin Nathwani is with the University of Waterloo, Waterloo, Canada (e-mail: nathwani@uwaterloo.ca). to achieve and balance multiple objectives: economic progress, job creation, environmental conservation, and low-carbon development.

Transforming the currently dominant carbon-intensive fossil fuel energy system to a green and sustainable one will therefore require strategic intervention from decision-making process [2]. This study covers essential dimensions of energy policy strategy for China's green growth and makes recommendations on how they can contribute to green growth strategies. It aims to provide a long-term comprehensive strategic energy framework (LCSEF) to decouple energy consumption and $\mathrm{CO}_{2}$ emissions from economic growth in China. In another words, forming of a Green, Reliable, Effective, Affordable, and Thrifty (GREAT) energy system that decouples energy service from carbon emission is the center piece of China's energy greening strategy.

Accordingly, a solid legal basis, carbon pricing, green technical innovation and investment, behavioral and managerial improvements, and concrete roadmaps for the energy system are highly recommended to facilitate China's green growth. In so doing, a clear message regarding the benefits of low-carbon innovation, from energy efficiency solutions to clean energy products and services, from China's energy sector would serve as the major drives of change for delivering green growth at national, regional, and sectional levels.

\section{CONCEPTUAL FrameWORK}

The strengths, challenges, opportunities, responses, and effectiveness (SCORE) analytical framework was introduced to improve and optimize the former commonly used strengths, weaknesses, opportunities, threatens (SWOT) approach [3]. It has become a versatile alternative that goes beyond the SWOT for strategy planning, evaluation, adjustment, and optimization [4], [5].

SCORE addresses those requirements with a SWOT-like checklist as a framework for strategy, where: S stands for strengths, services, or support that already have the existing capabilities and resources; $\mathrm{C}$ stands for challenges that need to be overcome, or capabilities that need to obtained; $O$ stands for options, opportunities, or risks that exist on the way to meet the desired goals; $\mathrm{R}$ stands for responses, returns, or rewards that are triggered by the chosen strategy; E stands for effectiveness of possible impacts of the chosen strategy on overall effectiveness measured as efficient, reliable, elegant, appropriate, and integrated.

An important differential feature of the SCORE, in contrast to SWOT, is a dynamic and cyclical process under which one or more gaps between present, past, and future expectations 
can be identified before effective evaluations of actions are provided. This report aims to compose a long-term energy strategy to build a GREAT energy system for China's green growth by employing the SCORE methodological approach (see Fig. 1).

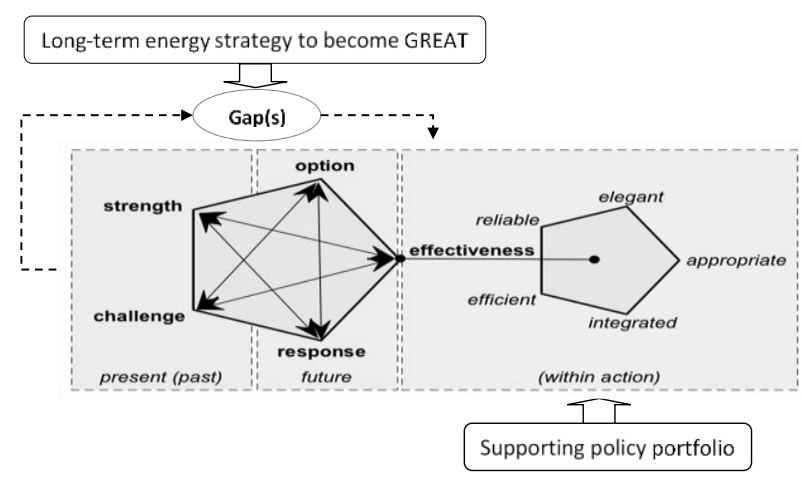

Fig. 1. Conceptual analytic structure (adapted from T. Graves, 2008).

\section{SCORE ANALYSIS FOR A GREAT ENERGY SCHEME}

\section{A. China Profile}

Submit your manuscript electronically for review. Based on the statistics and database from the World Bank, the International Energy Agency, the World Energy Council, and the BP Energy, China's energy-related indicators including its development situation and trend are summarized and analyzed as follows:

Population: The total population of China stood at 1.35 billion in 2012, consisting of nearly 19 percent of world's total population. Fortunately, the net increasing of China's population is expected to stop around 2020.

Economy: China became the second largest economy in the world after the United States in terms of both nominal GDP and purchasing power parity (PPP) in 2012. China is also the largest exporter, second largest importer, and the biggest manufacturing hub of goods globally.

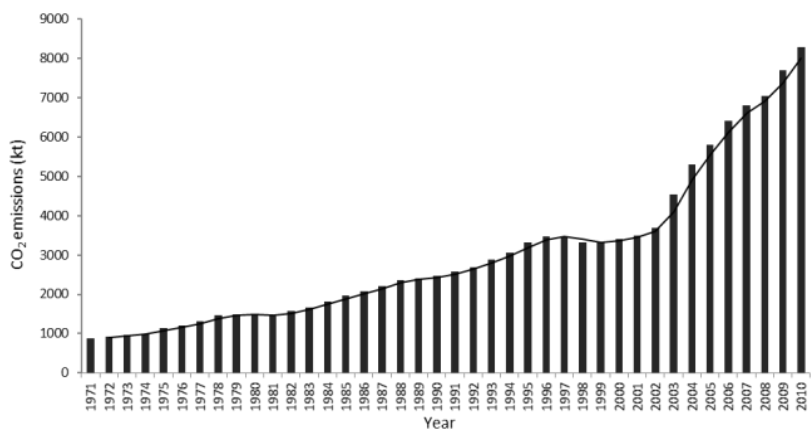

Fig. 2. China's CO2 emissions from 1971 to 2010 (source: World Band statistic).

Climate change: China has had the largest carbon emissions since 2007 and made up nearly one fourth of global emissions in 2010 (8286.89 kt) (see Fig. 2). China's emissions have more than doubled since 2000, which is projected to increase to nearly 30 percent of global emissions by 2050 under a "business-as-usual" scenario [6].

Energy consumption: China's energy consumption grew by 136 percent as its share of global energy demand increased from 10 percent to 21 percent from 2001 to 2011 , resulting in increasing international energy import. The total primary energy consumption reached 2735.2Mtoe and ranked second after the U.S. in 2011.

Energy supply mix: Coal still dominated China's energy supply mix in 2011, consisting of 68.2 percent in the supply structure, followed by oil (16.2 percent), natural gas (3.9 percent), hydro (2.2 percent), biomass and waste (7.9 percent), nuclear ( 0.8 percent), and other renewable (geothermal, solar, and wind, 0.8 percent) (see Fig. 3).

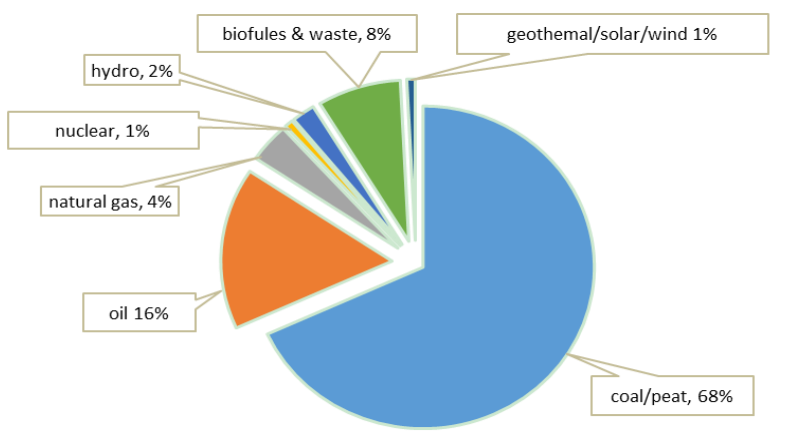

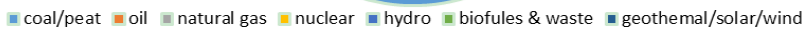
Fig. 3. China's energy supply mix in 2011 (source: Pew Environment Group, Goldman Sachs research estimates).

Energy foreign dependence degree: China has become a net energy importer since 1999, and its energy external dependence increased by more than 10 percent during the past decade, resulting in a big impact on world energy markets. Particularly, China's oil consumption has grown fast and made itself the second largest net oil importer in 2011 in the world (see Fig. 4).

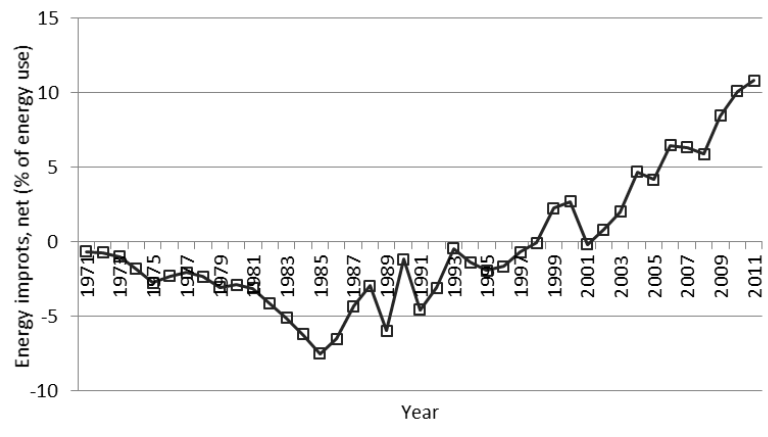

Fig. 4. China's net energy imports percentage of energy use during 1971-2011.

\section{B. Strengths for GREAT}

After decades of development, a fairly stable, complete, comprehensive energy sector, including the supply-demand system, energy market, and energy industry, has been developed to provide reliable energy service for the country.

Supply ability and energy security: China produced 2230 Mote of total primary energy in 2011, which makes it the biggest energy supplier that accounts for almost one fifth of global energy production. Additionally, the country's energy self-sufficient rate is almost ninety percent and its emergency energy-supply capability keeps improving.

Energy conservation: With the promotion and application of the Energy Conservation Law, China's energy intensity dropped by 20.7 percent during 2006 to 2011, bring in approximately 500Mtoe energy conservation.

Development in non-fossil energy: In 2012, approximately 
15.66 GW of new renewable energy capacity (excluding hydro) was installed and made the total renewable capacity in the country to reach $69.61 \mathrm{GW}$ by the end of 2012. The installed generating capacity of hydropower also reached 249 GW, making China the biggest renewable energy country globally. The development of the non-fossil fuels has contributed to more than 600 million tons of carbon dioxide mitigation every year.

Progress in energy science and technology: A fairly complete and advanced system of energy technologies for energy exploration, exploitation, transportation, transformation, and utilization has been formed. Some technologies have reach the world advanced level, such as the direct coal liquefaction and coal-to-olefins technologies, the designing and manufacturing of $700,000-\mathrm{kw}$ hydraulic turbine generators, high-temperature gas-cooled reactors and fast reactors research, and the extra-high-voltage DC/AC power transmission technology and manufacturing.

Improvement in civil energy use conditions: In an attempt to enhance the overall level of energy service, many civil energy projects and works have been executed over the last decade to provide rural areas with modern energy service such as the first and second west-east gas pipelines, the Qinghai-Tibet electricity network project, electric power facilities construction project, the combined heat and power projects.

Gradually improved marketization level: After partly market-oriented reform in the energy system, the market mechanism is playing an increasing role in resource allocation including these changes or phenomena: diversified investors and fast growing private investment can be found in the energy arena; free-market pricing has been launched for coal; government administrative and enterprise management have been separated into state-owned power firms; a feed-in tariff (FIT) system has been found for wind and photovoltaic power generation; a carbon trading scheme has been introduced into seven pilots; a number of laws and regulations have been amended and published in the past few years.

\section{Challenges for Being GREAT}

The inevitable process of internationalization, industrialization, and urbanization has underpinned China's vigorous economic growth but created a very large increasing environmental burden anticipated with growth energy demand. Additionally, special characteristics of its economy, energy, and environment remain barriers to the pursuit of green growth.

Limited legislation system and policy tools: Although China has some energy-related laws including the National Electrical Codes (1995), the Coal Law (1996), the Energy Saving Law (1997), and the Renewable Energy Law (2005), no consistent and comprehensive national-level energy law has been enacted. Strengthened legislative energy governance is also needed to lay the foundation of China's energy marketlization and the flexibility of policy tools adoption. Currently, the energy administration system still relies heavily on the traditional policy tools such as loans, subsidies, and tax breaks.

Fragmented administrative regime: without a single administrative institution with primary authority, the governance of the energy system governance is scattered into more than ten departments, including the National Energy Commission, the National Development and Reform Commission, the National Energy Administration, the Ministry of Land and Resources, the Ministry of Water Resources, the Ministry of Industry and Information Technology, the Ministry of Finance, and certain large state-owned energy corporations, which has hindered the efficiency and effectiveness of energy governance [7].

Geographical mismatch between the supply and demand: The energy resource is unevenly distributed. A wide spatial gap between the energy supply and energy consumption has posed serious challenges to the development of a green, sustainable energy system. Long-distance transmission increases energy loss, environmental pollution, transportation load, and infrastructure investment, resulting in low utilization efficiency. It also raises the concern of energy security and energy curse [8].

Coal issue: Coal, which provided 66 percent of China's gross domestic energy consumption in 2011 [9], is a main reason for China's air pollution and environmental deterioration. China's energy endowment is characterized as "rich in coal, but lack of oil and gas", leading to an extremely high coal consumption that impedes the process of diversification of the energy supply and consumption structure. Moreover, relying on fossil fuels has created the "locked-in effect" as the coal-related industries have expanded to a great extent over the past decades.

Prominent resources restraint: With its large population, China is poor in a per-capita average of energy resources by world standards. Its per-capita shares of coal, petroleum, and natural gas account for 67 percent, 5.4 percent, and 7.5 percent of the world's averages, respectively Meanwhile, the per-capita average of arable land is less than 30 percent of the world's average, which has hindered the development of biomass energy [10].

Low energy efficiency: Although the country has seen prominent enhancement in its energy intensity, the energy consumption per unit of GDP is still much higher than those of developed countries and the world average level. Insufficient technology supply, technology breakthrough, and technological innovation are hindering the escalation and clean development in the energy-intensive and carbon-intensive industries.

Grave environmental pressure: A high carbon-and pollution-intensive energy supply and consumption regime has posed a serious impact on China's eco-environmental system. Eco-environmental deterioration such as air pollution, soil acidification, and extreme weather triggered by the discharge of carbon dioxide, sulfur dioxide, nitrogen oxides and toxic heavy metals is decreasing the bearing capacity of eco-environmental system.

Low interconnection capability: Despite China leading the world in terms of renewable installation capacity, the development of green energy industries is still compromised by low grid-connection capacity. For example, more than 12 percent of the wind power was discarded in 2011 due to grid interconnection limitations [11]. 


\section{Options and Opportunities for Being GREAT}

According to the Oil \& Gas Journal (OGJ, 2013), EIA reports (EIA, 2013), BP Energy Statistics (BP, 2013), BP Energy Outlook 2030 (BP, 2013), China Wind Energy Development Roadmap 2050 (IEA \& ERI, 2011), and A special report on renewable energy in China, China's inner potential to be green can be summarised as follows:

Wind power: China has the largest wind energy in the world, and the wind power has been identified as a key growth component of the country's economy. In 2010, China replaced the U.S. as having the largest installed wind-power capacity around the world as its added and cumulative capacity reached $18 \mathrm{GW}$ and $43 \mathrm{GW}$, respectively. With its blessed wind resource (on-shore and off-shore), China's installation capacity is expected to reach $200 \mathrm{GW}$ by $2020,400 \mathrm{GW}$ by 2030 , and $1000 \mathrm{GW}$ by 2050 to provide 5 percent, 8 percent, and 17percent of total electric demand.

Solar power: The domestic PV panel industry has been damaged by the European debt crisis; yet, the generation capacity is expected to be $1200 \mathrm{GW}$ by 2050 with the recovery of the overseas market, development of domestic market, and breakthrough in core technologies.

Hydropower: With the help of the three-gorgeous dam and the $\mathrm{Nu}$ river dam, China has gained 542 million $\mathrm{KW}$ technically exploitable hydropower resources and made itself the first installed capacity in the world. Currently, less than 30 percent of total hydropower is in use, leaving plenty of room for development in the future. By 2015, the amount of energy from the conventional hydropower and pumped storage is projected to reach $325 \mathrm{GW}$ in total.

Waste to energy: Boosted by the concept of the circular economy and resources conservation, municipal waste has been indicated as a useful way to turn waste into service. By 2030, 30 percent of China's municipal solid waste is expected to be burned for electric generation.

Carbon capture and storage: The viable storage capacity of Carbon capture and storage (CCS) is estimated at nearly 2000 Gt. However, the application of CCS technology is still in its early days and faces a lot of challenges.

Oil and gas: China's proven reservation of oil is estimated at 20.4 billion barrels, and the conventional natural gas reserve is approximately 2.46 trillion cubic meters. Meanwhile, recoverable reserves of unconventional gas, such as coal bed methane (CBM) and shale gas is estimated at 136 trillion cu m, more than three times than the conventional gas reserves.

Coal: Coal has played a significant role in China's energy supply for decades. Compared with other fossil fuels, coal is relatively abundant in China and the proved reserve at the end of 2012 was 114,500 million tons. Yet, due to its growing energy demand, China has been a net importer of coal since 2009.

Nuclear: Nuclear power also has the potential to replace coal with its stable ability to meet the base-load demand. It is evaluated that $653 \mathrm{GW}$ of nuclear power is expected to generate 4,569 TWH power by 2050 to meet China's CO2 emissions reduction target.

Moreover, external opportunities such as increasing technological spillovers combined with foreign direct investment (FDI), international and intergovernmental communication and cooperation, abundant experiences and references from the execution of other countries' energy policies, and the dramatically growing clean-tech global market have provided the Chinese energy sector with help, guidance, and support to become GREAT as well.

\section{E. Responses to and Rewards of A GREAT System}

The current development paradigm of the energy sector is likely unsustainable and poses a significant challenge for long-term prosperity. In an attempt to overcome the obstacles and develop a sustainable economy, China needs a GREAT energy development scenario to facilitate the transition and transformation of its energy system.

Referencing the studies from the International Energy Agency (IEA), China Energy Research Institute (ERI), and the Lawrence Berkeley National Laboratory (LBNL), various scenarios are drawn to clear the long-term trajectories of China's energy and carbon emissions to 2050 [12].

By 2050, China's primary energy consumption is projected to reach between 4,000 to 6,000 Mote in different scenarios due to its population and economic aggregate. Moreover, 36 Mote energy is required to facilitate CCS to capture $500 \mathrm{Mt}$ $\mathrm{CO}_{2}$, resulting in 5,517 Mote total energy use in 2050 under the continued improvement scenario (CIS) scenario.

$\mathrm{CO}_{2}$ emissions under different scenarios approach will reach their peak between 2025 and 2040. For ERI scenarios, China's carbon emission will range from 5,000 to 12,000 Mt with different development pathways, such as efficient scenario, incremental and accelerated improvement scenario (CIS, AIS), low carbon scenario, and accelerated low carbon scenario.

\section{LONG-TERM COMPREHENSIVE STRATEGIC ENERGY FRAMEWORK}

A Green, Reliable, Efficient, Affordable, and Thrifty (GREAT) energy development scheme is promoted as a key component of a long-term comprehensive strategic energy framework (LCSEF) to secure China's green growth as below.

\section{A. Stress Energy Conservation and Energy Efficiency}

For example, given the low per capita hold of resource and the grave limitation of environmental capacity, energy conservation is and will stay first on China's energy policy menu. This energy conservation requires asks for advanced energy storage, recycling, and transportation facilities, as well as active participation of the whole society.

Furthermore, energy efficiency is a key and fundamental component of green growth strategies because it offers additional benefits such as climate change mitigation, environmental impact reduction, and job creation. It also helps business become productive and competitive. Therefore, energy efficiency improves on both the macro and micro levels as well as the different stages of energy exploration, transportation, storage, distribution, and utilization.

\section{B. Escalate the Development of Alternative Energy}

China has abundant hydro, wind, solar, and waste and 
biomass resources that provide the country a tremendous potential to advance its energy system. Vigorously developing alternative energy, namely new and renewable energy, is a key strategic measure for the systematic transition and escalation of its energy system, which, in turn, facilitates the eco-environment protection, job creation, and emissions mitigation.

China's hydropower generation capacity should be released gradually to replace coal and boost local employment and economic development; nuclear power should be utilized in a safe way, while the exploitation of nuclear waste is expected to exert double dividends in terms of energy supply and threaten elimination; wind power should be explored through the improvement of interconnecting ability and the development of its off-grid application; solar power should be harnessed by boosting domestic consumption and progressing in manufacturing technology; large-scale market applications are the key target of waste and biomass power generation.

\section{Promote Clean Use of Fossil Energies (Coal)}

Fossil fuel, including coal, oil, and gas, will continue to dominant as the energy supply for decades to come both in China and around the world. China is facing an even higher challenge than other countries to clean up the energy mix due to its long coal-dominated history, abundant coal endowment, and long-distance transportation of coal products.

To manage this issue, the clean and effective use of coal is the first choice to lower its environmental impact while providing enough energy supply at the same time. Development and application of clean coal technology, escalation of coal-related industries, and the local utilization of coal are advocated to make better use of the resource; alternatively, China should take the advantage of its prospective unconventional oil and gas resources to abate carbon emissions, narrow the geographic gap between energy supply and demand, enhance energy security, and create more green jobs.

By putting forward the clean development of fossil energy, multi-targets such as energy self-sufficient, emission reduction, job creation, and local economy growth are likely to be met efficiently.

\section{Advocate Comprehensive Carbon Management}

As a main target of climate and environmental governance, the energy system is key to reduce carbon emissions.

In additional to renewable development and clean use of fossil fuels, carbon management, including direct and indirect carbon control, has become another crucial way to address the climate change issue.

In another words, a comprehensive framework that covers carbon cap, capture, storage, and use should be advocated to carbon emissions mitigation.

\section{E. Vigorously Develop the Energy Science and Technology}

In the short term, China's energy science and technology fields should develop energy efficiency and fossil fuel clean utilization technologies, such as zero emission, grid integration capacity improvement for renewable sources, the Integrated Gasification Combined Cycle (IGCC);
In the mid-term, it should provide technologies for carbon capture, usage, and storage that are mature and can meet the needs for large-scale application;

In the long term, technologies should be available for new materials application and for new-renewable energies harness.

\section{POLICY Alternatives to ACHIEVE THE EFFECTIVENESS OF SCORE}

A Series of strategies are recommended to boost the $[\mathrm{r}]$ evolution of China's energy system to achieve a prosperous economy, society, and environment. Systematic, integrated, coherent, multiple, and cross-sector energy management and governance are needed to form a policy portfolio to fulfill long-term comprehensive strategies to facilitate the transformation and transition in the energy system.

To this end, a firm legitimate-based regulatory paradigm should be set up in line with the scientific selection, combination, and innovation of energy policy instruments. In addition to referring to other successful examples from around the world, a renewed policy portfolio is recommended for China.

\section{A. Build a Strong but Flexible Regulation System and a Consistent Administration Scheme}

To insure the development of clean energy, the Chinese government has built an administrative regime based on the Renewable Energy Law, launched in 2005. However, current regulations are far from efficient and effective. Desired results been not been met and various problems have arisen/been revealed. Further strengthening of measures to enhance the insurance support for full development and [r] evolution of the energy system may be necessary. From this perspective, a strong but flexible administrative regime including supporting policies as well as an effective regulatory system is needed to facilitate the evolution of China's energy system.

\section{B. Increase Green Investment and Public Procurement Schemes}

Both the expansion and escalation of alternative energy rely heavily on the development of clean technology consists of capital- and knowledge-intensive activities.

Further development and implement of financing schemes that facilitate green growth and energy efficiency are needed; alternatively, the government is expected to take the responsibility to boost the large-scale application of green technology through public procurement.

The creation, selection and combination of policy instruments that are appropriate, effective, and flexible is crucial to attract sufficient investment and achieving political goals. Flexibility and credibility of policy portfolios will make decision-makers sensitive and react to market changes quickly, as well as guarantee the implementation of clean-tech projects, which, in turn, will benefit the market to facilitate the development of clean-tech.

\section{Strengthen Demand-Side Management}

Demand-side management (DSM), which focuses on grade and flexible utilization of resources, is a key component of 
energy supply, and plays an increasingly important role in energy conservation, energy efficiency, energy resilience, energy optimization, and energy security.

China could carry out the DSM scheme by advocating demand-side control technological innovation, increasing investment in DSM research, facilitating information exchanges for DSM programmes, and making scientific and comprehensive DSM development roadmaps.

\section{Leverage the Best Available Technology and Encourage Reverse Innovation}

The transformation of energy system relies greatly on technological innovation.

Therefore, China should make full use of the Best Available Technologies (BAT) that fit its development background to lower the cost and gain good outcomes; alternatively, incentives should be provided by the government to encourage reverse innovation to set up China's own energy core technological system that supports and fosters the transition of its energy system.

Furthermore, from the perspective of the Life Cycle Analysis (LCA), priorities should be given not only to the fields of mining and processing, but also to resource recycling, environment protection, and pollution prevention in order to provide overall sufficient science and technology support.

\section{E. Enhance the Overall Capacity and Effectiveness of Carbon Management}

Direct and indirect methods should be promoted to improve the overall capacity and effectiveness of carbon management. A feasible mechanism for carbon pricing is called for to facilitate both clean generation technologies and the large-scale application of carbon capture and storage (CCS) [6].

By 2012, more than 30 jurisdictions adopted various carbon pricing schemes to address the market failure caused by $\mathrm{CO}_{2}$ emissions. For China, four direct-controlled municipality (Beijing, Tianjin, Shanghai, Chongqing) and three jurisdictions (Hubei, Guangdong, and Shenzhen) were selected in 2011 as pilot projects to test the implementation of carbon trading. However, the results are not very satisfactory because various problems have emerged. Compared with cap-and-trade systems, carbon taxes, with their flexibility, efficiency, maturity, simplicity, and stability, is highly recommended to address carbon mitigation.

\section{F. Advocate a Green Energy Culture}

The green transformation needs broad public support because the public awareness has become an essential aspect of energy and climate management. Social behavior, awareness-raising, and energy literacy are key components of green energy culture.

Lacking of information, knowledge, and understanding regarding the nature and role of energy in the world and in the daily lives of the public is identified as an underlying factor that may prohibit the development of a green economy. More efforts should be made to increase awareness in the public about the environmental consequences of current unsustainable patterns of production and consumption, and about the potential for improvements through green growth and increased energy efficiency.

\section{G. Expend Multilevel Governance and Cross-Sector Cooperation}

Both the energy [r] evolution and climate change cross-cut multi-lateral issues that cannot be resolved by a single party. It therefore calls for multilevel governance and cross-sector cooperation.

It is necessary for China to be active in international engagement in the arena of energy and climate consultations and negotiations to gain more understanding about each other and enhance multilateral cooperation; furthermore, a multilevel governance perspective should be adopted to improve government administrative efficiency. Dialogue among the stakeholders, such as central government, local government, business, community, and public, should be advocated to a large extent.

\section{ACKNOWLEDGMENT}

The authors are grateful for the support provided to by the National Natural Science Foundation (NSF) of China under the international (regional) cooperating research project called "International Comparison on the Theories and Practices of Green Growth (PN: 71320107006)" headed by Professor Chunyou $\mathrm{Wu}$ from Dalian University of Technology, and Professor Jatin Nathwani acknowledges the support of the Ontario Council of Universities (COU) through funding of the Ontario Research Chairs Program in Public Policy.

\section{REFERENCES}

[1] OECD Green Growth Studies: Energy, Paris: OECD Publishing, 2011.

[2] Green Growth-Energy: Industry Opportunities for Australia, Melbourne: Australian Academy of Technological Sciences and Engineering, 2013.

[3] T. Graves, SEMPER and SCORE: Enhancing Enterprise Effectiveness, Essex: Tetradian Books, 2008.

[4] UNEP, Green Economy Scoping Study Synthesis Report, Barbados: COT Printery, 2012.

[5] W. Moore, "Green economy in practice: The Barbadian perspective," Caribbean Green Economy Action Learning Group, Working Paper No. 52013.

[6] A. Gambhir et al., "China's energy technology options to 2050," Grantham Institute for Climate Change, UK: London, 2011.

[7] S. Downs, "China's new energy administration," China Business Review, vol. 35, no. 6, pp. 42-45, 2008.

[8] SCIO, China's Energy Conditions and Policies, Information Office of the State Council of the People's Republic of China, 2007.

[9] M. Adams, A Greener Shade of Grey: A Special Report on Renewable Energy in China, The Economist Intelligence Unit Limited, 2012.

[10] SCIO, China's Energy Policy 2012, Information Office of the State Council of the People's Republic of China, 2012.

[11] J. F. Li et al., China Wind Energy Outlook 2012, Beijing: China Environmental Science Press, 2012.

[12] N. Zhou, D. Fridley, N. Khanna, J. Ke, M. McNeil, and M. Levine, "China's energy and emissions outlook to 2050: Perspectives from bottom-up energy end-use model," Energy Policy, vol. 53, pp. 51-62, 2013.

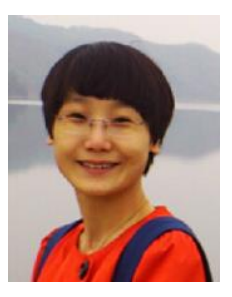

Xiaoling Wang has received her B.A, M.A, and M.E.S degrees in economics, regional economies, and environmental studies. Currently, she is a joint doctoral candidate at the Dalian University of Technology and University of Waterloo. She is specializing in environmental and energy management study. Her research interests are the path and mechanism analysis of green growth. 


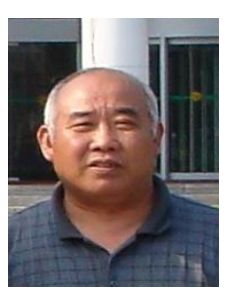

Chunyou Wu is a professor and academician in the International Academy of Ecology and Life Protection Science, Department of Public Information of United Nations. He is the dean of Technology Institute of Eco-Planning and Development Studies at the Dalian University of Technology. His contributions are in the fields of decision analysis, eco-planning and development management and technological innovation management.

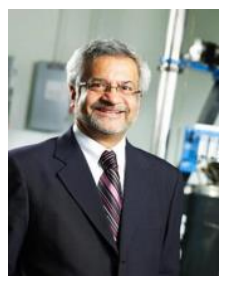

Jatin Nathwani is the Ontario research chair in Public Policy for Sustainable Energy; he is a professor at the Faculty of Engineering and Faculty of Environment at the University of Waterloo. He is also the executive director of Waterloo Institute for Sustainable Energy (WISE). His contributions are in the areas of energy policy developments, life cycle management of risk and decision-frameworks for managing life safety risks, and evaluation of regulatory and market based instruments for achieving environmental objectives. 

Electrical \& Geothermal Energy 
